\title{
PRIMÓRDIOS DO ADVENTISMO NO RIO DE JANEIRO (1888-1906)
}

\author{
Daniel Fernandes Teodoro*, Elder Hosokawa, Lucas Almeida dos Santos, Silas Figueredo Barrella.
}

\section{Resumo}

O presente trabalho propõe estabelecer uma análise sobre o desenvolvimento da história do adventismo no Brasil a partir do Rio de Janeiro, tendo em vista as concepções tradicionais apresentarem versões centralizada nos estados do Paraná, Santa Catarina e Rio Grande do Sul. Através de métodos historiográficos, buscou-se identificar os desafios encontrados na cidade, atrelados a perspectiva evangelística da IASD (Igreja Adventista do Sétimo Dia) e quais as razões que impossibilitaram o estabelecimento da fé adventista na capital federal do país até então. As principais fontes históricas analisadas foram os fascículos da Review and Herald, periódico adventista norte-americano. Com isso, o trabalho buscou analisar a origem memorialista de uma escrita unívoca à região Sul e desmonta-la adicionando uma nova interpretação.

\section{Palavras-chave:}

Adventismo, Primeira República, Rio de Janeiro.

\section{Introdução}

O presente estudo tem como objetivo questionar o padrão instituído na escrita da história do adventismo no Brasil, analisar os desafios encontrados no Rio de Janeiro e compreender como a perspectiva evangelística da igreja adventista impossibilitou o estabelecimento da fé adventista na capital federal.

Em 1874, iniciou-se a expansão missionária da igreja com o envio de J. N. Andrews à Europa. Diante da primeira expedição, a igreja começou a olhar para outras regiões do mundo e na busca por alcançar novos campos, utilizou como estratégia o envio de literaturas, das quais as primeiras chegaram ao Brasil a partir de 1880. Posteriormente, foi enviado ao continente sul americano o primeiro missionário, L. C. Chadwick, em junho de 1891 para uma missão de reconhecimento. Com isso, iniciaram os preparativos para a chegada dos vendedores de literatura denominacional, C. A. Nowlen, E. W. Snyder e Albert B. Stauffer que realizaram o trabalho no Uruguai, Argentina e Brasil. Porém, o primeiro desafio estava na questão do idioma, visto que as publicações eram incompatíveis aos idiomas falados (GREENLEAF, 2011).

Tradicionalmente, a história do adventismo no Brasil é contada a partir do estado de Santa Catarina. Em uma destas obras intitulada " $A$ chegada do adventismo no Brasil", Borges (2000) apresenta a cidade de Brusque como berço do adventismo em meados da década 1880 , em uma história voltada unicamente para região Sul do Brasil. Contudo, esta interpretação instituiu uma generalização totalizante para compreensão do respectivo tema, tendo em vista essas narrativas apresentam 'uma chegada', não 'a chegada' (CERTEAU, 1982). Categorizar nomenclaturas e unificar interpretações é uma narrativa saturada, desde o século XIX com a lógica positivista (BURKE, 1992). As publicações norte-americanas não alcançaram apenas o porto de Santa Catarina. Não por acaso, em 1900, a primeira publicação do periódico $O$ Arauto da Verdade, ocorreu na Typographia e Lithographia, da firma Almeida Marques \& Cia, localizada na Travessa do Ouvidor, Rio de Janeiro (LESSA, 2000). Contudo, já em 1888, a
Review and Herald nos Estados Unidos anunciava um leitor interessado residente no Rio de Janeiro. O que suscita uma interrogação às explicações estabelecidas (VALENTINER, 1888).

\section{Resultados e Discussão}

Esta pesquisa teve caráter essencialmente bibliográfico e como principais fontes utilizou-se os fascículos da Review and Herald elencados em uma discussão historiográfica a fim de questionar interpretações memorialistas. Desta forma, foi possível perceber que a narrativa tradicional foi constituída como discurso motivada por um "lugar de produção" (CERTEAU, 1982). Além disso, através da análise em escritos de Ellen G. White e da situação que envolvia o Rio de Janeiro na época, identificou-se perspectivas relativas ao afastamento dos centros urbanos, o que, portanto, poderia ter influenciado a fuga dos missionários da capital federal.

\section{Conclusões}

A história do adventismo é plural e não pode ser restrita aos estados do Paraná, Santa Catarina e Rio Grande do Sul. Portanto, o estudo historiográfico deste tema sublinha a necessidade de interpretações, cuja narrativa não esteja envolvida no memorialismo.

\section{Agradecimentos}

Agradecemos ao UNASP-EC e ao Centro de Pesquisas Ellen White Brasil por disponibilizar os materiais necessários para conclusão desta pesquisa.

BORGES, Michelson. A chegada do adventismo no Brasil. 1. ed. Tatuí, SP: CPB, 2000.

BURKE, P. Abertura: a nova história, seu passado e seu futuro. In: BURKE, P. (Org.). A escrita da história: novas perspectivas. 1 ed. São Paulo, SP: Unesp, 1992.

CERTEAU, M. A escrita da história. 1 ed. Rio de Janeiro, RJ: Forense Universitária, 1982

GREENLEAF, F. Terra de Esperança: Desenvolvimento da IASD na América do Sul. Tatuí, SP: Casa Publicadora Brasileira, 2014.

LESSA, R. Casa Publicadora Brasileira: 100 anos. Tatuí, SP: CPB, 2000. SCHWARZ, R.; GREENLEAF, F. Portadores de Luz: história da IASD . Engenheiro Coelho SP: CPB, 2016.

VALENTINER, T. Brazil. Review and Herald. v. 65, n. 46, p. 732-732, nov. 1888. Disponível em:

<http://documents.adventistarchives.org/Periodicals/RH/RH18881120-V65-

46.pdf>. Acesso em 29 mai. 2019. 